\title{
HEGEL, RAWLS E O TEMA DA RECONCILIAÇÃO
}

Cesar Augusto Ramos ${ }^{*}$

RESUMO - O propósito deste artigo é analisar as relações de Rawls com o pensamento político de Hegel - considerado pelo primeiro como um "liberalismo da liberdade" - no que diz respeito ao tema da reconciliação. Primeiramente, vamos analisar o conceito hegeliano de reconciliação. Em segundo lugar, procederemos a uma leitura de alguns aspectos da teoria rawlsiana a partir deste conceito para, finalmente, destacar a valorização do mesmo na obra de Rawls. Tratase, portanto, de verificar de que forma a recepção crítica do tema hegeliano da reconciliação pode estimular um ajuste do liberalismo político às exigências da realidade histórica das sociedades liberais modernas, cobrindo, assim, um déficit do liberalismo político em relação às críticas comunitaristas, sobretudo, a questão do normativismo abstrato.

PALAVRAS-CHAVE - Hegelianismo. Liberalismo. Liberdade. Reconciliação.
ABSTRACT - The purpose of this article is to analyze the relations between Rawls and Hegel's political thought - considered by the former as a "liberalism of freedom" - regarding the theme of reconciliation. Firstly, we will analyze the Hegelian concept of reconciliation. Secondly, we will proceed to a reading of some aspects of the Rawlsian theory based in that concept, in order to eventually underscore its value in Rawls' work. Therefore, the article verifies in which way the critical reception of the Hegelian theme of reconciliation can stimulate an adjustment of the political liberalism to the demands of the historical reality of modern liberal societies, covering, in this manner, a deficit of political liberalism in relation to communitarian criticisms, especially, the question of abstract normativism.

KEY WORDS - Hegelianism. Liberalism. Freedom. Reconciliation.

\section{Introdução}

Na filosofia política contemporânea, o debate entre os filósofos vinculados a posições do liberalismo político com destaque a J. Rawls e os assim chamados comunitaristas revela a presença polêmica de temas de inspiração hegeliana. ${ }^{1}$ Uma

Pontifícia Universidade Católica do Paraná - PUCPR/CNPq.

Com a publicação da Teoria da Justiça de Ralws, da obra de R. Nozick, Anarchy, State and Utopia (1974) e de R. Dworkin, Taking Rights Seriously (1977), todas elas na perspectiva da renovação do liberalismo, surge, a partir da década de 80, nos Estados Unidos da América, uma reação contra o individualismo neoliberal. Essa reação foi provocada pelas críticas de autores denominados comunitaristas. Dentre esses autores, destacam-se: Alastair MacIntyre. After Virtue (1981), Michael Sandel. Liberalism and the Limits of Justice (1982), M. Walzer. Spheres of Justice: Defense of Pluralism and Equality (1983), C. Taylor. Philosophy and the Human Sciences: Philosophyical Papers (1985) e Sources of the Self (1990), J. Raz. The Morality of Freedom (1986). Na relação com Hegel, especial destaque deve ser dado a C. Taylor.

\begin{tabular}{|l|l|l|l|l|l|}
\hline VERITAS & Porto Alegre & v. 52 & n. 1 & Março 2007 & p. 25-42 \\
\hline
\end{tabular}


das tarefas importantes para se avaliar a justeza dessa polêmica consiste no exame das relações entre Rawls e Hegel, no sentido de se buscar pontos de proximidade e de distanciamento entre um e outro. Tal tarefa pode ajudar no esclarecimento de possíveis déficits da teoria rawlsiana apontados pela crítica comunitarista.

De início, é preciso observar que a "presença" hegeliana em Rawls, apesar de controversa, não pode ser depreciada - e, por isso mesmo, deve ser objeto de um exame crítico. O interesse do filósofo norte-americano por Hegel transparece, por exemplo, na relação que ele mantém com J. Dewey a propósito da avaliação do kantismo em sua filosofia. Rawls observa que

Dewey tinha começado sua carreira filosófica, como muitos outros no final do século XIX, sob a influência de Hegel. Seu gênio consistiu em adaptar o que havia de mais válido no idealismo de Hegel a uma forma de naturalismo específico de nossa cultura. Um dos objetivos de Hegel era ultrapassar os inúmeros dualismos que, segundo ele, deturpavam o idealismo transcendental de Kant, e Dewey, ao longo de toda a sua obra, compartilhou essa preocupação sublinhando com muita frequêencia o caráter contínuo daquilo que Kant havia separado de maneira tão radical. ${ }^{2}$

A intenção de Rawls nessa referência a Dewey demonstra que a sua teoria da justiça como eqüidade não se filia incondicionalmente a Kant, e nem deve ser considerada como uma teoria kantiana no sentido estrito.

Existem, portanto, pontos em comum entre a minha teoria e a de Dewey - observa Rawls - que se explicam por um desejo comum de superar os dualismos da doutrina kantiana. [...] O adjetivo kantiano exprime apenas uma analogia, não uma identidade; ele indica que minha doutrina se parece em boa parte, com a de Kant, e isso se dá a respeito de muitos pontos fundamentais, pelo que está bem mais próximo dela do que de outras doutrinas morais tradicionais que nos servem como termos de comparação. ${ }^{3}$

As críticas hegelianas (e por analogia algumas posições do comunitarismo) à tradição da teoria do contrato social e aos princípios do liberalismo são consideradas significativas por Rawls. O liberalismo político as reconhece, mas procura apresentar razões para verificar se elas são pertinentes ou não para contestar as principais teses da teoria da justiça como eqüidade. Rawls conclui que o propalado "conflito com o liberalismo parece não mais existir". As críticas que foram enunciadas, com base no legado de Hegel, dependem, diz ele, de uma concepção "equivocada", de uma "paródia" do liberalismo.

É no quadro dessas preocupações que se pode analisar a relação de Rawls sobretudo, aquela que se dá após a publicação de Uma Teoria da Justiça com o pensamento político de Hegel. ${ }^{5}$ Dois aspectos podem ser analisados nessa relação.

RAWLS, J. Justiça e Democracia. Trad. Irene Paternot. São Paulo: Martins Fontes, 2000, p. 46. Idem, p. 47, 48

RAWLS, J. Lectures on the History of Moral Philosophy, Cambridge: Harvard University Press, 2000, p. 369.

A leitura rawlsiana de Hegel é feita, principalmente, nas Lectures on the History of Moral Philosophy (2000). Nessa obra, Rawls faz uma análise da ética e da filosofia política hegeliana, tendo por base a Filosofia do Direito de Hegel. Uma atenção especial é dedicada a Kant, particularmente à 
Um primeiro diz respeito à inclusão de Hegel na linha do pensamento político que o filósofo norte-americano chamou de "liberalismo da liberdade". ${ }^{6}$ Um segundo aspecto refere-se ao debate crítico com o hegelianismo, particularmente em torno do tema da reconciliação, com vistas à correção de alguns elementos do normativismo abstrato da teoria da justiça, que será analisada a partir dos ajustes feitos na década de 80 e início dos anos 90 do século passado sob a ótica do liberalismo político inserido na realidade histórica do "pluralismo razoável" das sociedades liberais democráticas modernas.

No que se refere ao primeiro aspecto, ou seja, à compreensão da filosofia política de Hegel, dentro do quadro geral do pensamento liberal, Rawls anuncia o seu propósito dizendo: "Eu interpreto Hegel como um liberal reformista moderadamente progressista, e vejo seu liberalismo como um importante exemplo na história da filosofia política e moral do liberalismo da liberdade". ' Sobre essa última expressão, o autor esclarece que se trata de uma doutrina, cujos primeiros princípios são aqueles definidos pela liberdade política e cívica, os quais têm prioridade sobre outros princípios que poderiam ser evocados. Kant e J. S. Mill são outros teóricos que se colocam na mesma linha.

A tradição do liberalismo da liberdade parte pelo menos da Reforma e dá prioridade especial a certas liberdades básicas: liberdade de consciência e de pensamento, liberdade das pessoas e da livre escolha da vocação - liberdade da escravidão e da servidão - para mencionar alguns casos básicos. ${ }^{8}$

Com efeito, Rawls reputa a incorporação da vontade livre nas instituições sociais e políticas do Estado moderno como "uma de suas [de Hegel] mais importantes contribuições à filosofia moral e política". ${ }^{9}$ Essas instituições garantem e tornam possível a liberdade dos cidadãos, justificando a presença do Estado como momento mais alto da liberdade. Essa concepção de liberdade não significa associar a Filosofia do Direito "como uma tentativa de justificação do Estado prussiano em 1820 ou posterior", ${ }^{10}$ ou à defesa do "imperialismo germânico e dos nazistas". ${ }^{11}$ Rawls inclina-se para aqueles intérpretes (o hegelianismo de centro) para os quais "Hegel foi um liberal moderado e defensor do Estado constitucional moderno", em

Fundamentação da Metafísica dos Costumes, na análise histórica da filosofia moral. Mas o autor ocupa-se, também, com as idéias morais de Hume, de Leibniz e de Hegel. A leitura deste último foi compilada de um curso sobre filosofia política dado por Rawls em 1991. No texto publicado em 2000, a filosofia moral-política hegeliana é analisada em duas partes. Na primeira (Hegel I), alguns aspectos da Rechtsphilosophie são apresentados: § 1. Introdução; § 2. A Filosofia como Reconciliação; § 3. A Vontade Livre; § 4. A Propriedade Privada; § 5. A Sociedade Civil. Na segunda parte (Hegel II), a análise se concentra no tema Vida Ética e Liberalismo: § 1. Sittlichkeit: A consideração do Dever; § 2. Sittlichkeit: O Estado; § 3. Sittlichkeit: Guerra e Paz; § 4. Uma terceira alternativa; § 5. O Legado de Hegel como um Crítico do Liberalismo.

RAWLS, J. Lectures on the History of Moral Philosophy, p. 330

Idem, ibid

Idem, p. 366.

Idem, p. 331

Idem, p. 352.

Idem, ibid. 
que pese a força do Estado no sistema da Sittlichkeit hegeliana. E, justamente, é esse o ponto em que Hegel "parece se afastar do liberalismo tradicional" . ${ }^{12}$

Um segundo aspecto a ser abordado na relação do hegelianismo com a teoria do liberalismo político aquele que nos interessa nesse momento ${ }^{13}$ consiste em verificar que o interesse de Rawls por Hegel revela-se, não só pela leitura descritiva da história das idéias morais e políticas de autores que compartilham princípios filosóficos presentes na tradição do liberalismo da liberdade, como indica, também, uma preocupação filosófica, no sentido de avaliar as possibilidades teóricas do tema hegeliano da reconciliação.

Dessarte, primeiramente vamos, grosso modo, analisar este tema e o seu significado para a filosofia política de Hegel. Em segundo lugar, procederemos a uma leitura de alguns aspectos da teoria rawlsiana que evocam alguma proximidade ou analogias com o conceito da reconciliação e o que ele representa para a filosofia política. ${ }^{14}$ Trata-se, portanto, de verificar de que forma a recepção crítica desse

${ }^{12}$ Idem, p. 349. Apesar da inclusão de Hegel na linha do "liberalismo da liberdade", o seu liberalismo é, ainda, insuficiente, se comparado com as exigências de um conceito pleno da teoria política liberal. Na análise de Rawls, uma concepção liberal da justiça deve ter os seguintes (três) elementos principais: "primeiro, a especificação de certas liberdades, de oportunidades e de direitos básicos (como aqueles que são bem conhecidos nos regimes democráticos constitucionais); segundo, a determinação de uma prioridade particular atribuída a essas liberdades, a essas oportunidades e a esses direitos, examinando, muito especialmente, as reivindicaç̃es relativas ao bem geral e aos valores do perfecionismo; terceiro, medidas que assegurem a cada cidadão os meios adequados e polivalentes que permitam o uso eficaz de suas liberdades e de suas oportunidades básicas." (Justiça e Democracia, p. 277). Na nota correspondente a essa citação, Rawls acrescenta outras condições para formar uma idéia mais completa de uma concepção liberal de justiça: "1) a autoridade política deve respeitar o Estado de direito e uma concepção do bem comum que compreende o bem de cada cidadão; 2) a liberdade de consciência ou de pensamento deve ser garantida, e isso deve estender-se à liberdade de seguir a sua própria concepção do bem, ficando entendido que esta não deve violar os princípios de justiça; 3) direitos políticos iguais devem ser garantidos, assim como a liberdade de imprensa e de associação, o direito de constituir partidos que pressupõe, por outro lado, a eventualidade de uma oposição leal; 4) a igualdade das oportunidades e a livre escolha de um trabalho devem ser mantidas na perspectiva de oportunidades variadas; e 5) todos os cidadãos devem ter a garantia de uma distribuição eqüitativa dos meios materiais, de modo que eles sejam suficientemente independentes e possam tirar proveito da igualdade dos seus direitos básicos, das liberdades e das oportunidades eqüitativas" (idem, p. 277).

13 O primeiro aspecto mencionado nesta Introdução, ou seja, o estatuto do liberalismo de Hegel e as suas proximidades e diferenças com o liberalismo político de Rawls, a despeito das breves indicações apresentadas e que merecem um estudo mais aprofundado, não será abordado nesse artigo.

14 Michael O. Hardimon, no seu esclarecedor livro Hegel's Social Philosophy. The Project of Reconciliation, Cambridge: Cambridge University Press, 1994 (citado por Rawls como uma das fontes de referência para a sua interpretação do tema hegeliano da reconciliação), propõe três razões para se estudar esse tema: 1) o assunto tem a ver a com o nosso contexto cultural ligado com a noção de alienação. E Hegel faz um uso técnico do termo reconciliação no sentido de superação da alienação. 2) A segunda razão é de ordem acadêmica, pois a reconciliação se constitui na principal categoria organizadora e no objetivo principal da filosofia social de Hegel. 3) A terceira razão é de ordem filosófica, ou seja, o tema da reconciliação ainda está presente como questão filosófica tradicional. A preocupação com esse tema não está tão distanciada de alguns representantes da filosofia contemporânea. "Assim, por exemplo, John Rawls sustenta que um dos vários papéis que a filosofia política possui, como parte da cultura, é a 'reconciliação' - papel que foi enfatizado por Hegel, como observa Rawls" (p. 10). Hardimon assevera que Hegel foi o primeiro pensador moderno que definiu a reconciliação como o grande objetivo da filosofia política, e que a 
conceito pode, pelo menos, estimular um ajuste do liberalismo político às exigências da realidade histórica das sociedades liberais modernas, cobrindo, assim, um déficit que ele apresenta em relação às críticas comunitaristas.

\section{0 conceito hegeliano de reconciliação}

O conceito de reconciliação (Versöhnung) associado ao de realidade efetiva (Wirklichkeit) e seu processo de efetivação (Verwirklichung) constitui um ponto nodal no pensamento hegeliano. Para Hegel, a reconciliação possui dois aspectos ou faces interligadas: o aspecto lógico-histórico do realismo da Idéia que se perfaz como realidade efetiva e o aspecto institucional de integração do indivíduo (e da sua liberdade subjetiva) ao seu tempo (modernidade), conciliando-o com o caráter ético-substancial da moderna eticidade (Sitllichkeit).

A reconciliação, analisada do ponto de vista do primeiro aspecto, isto é, sob o prisma das categorias conceituais lógicas e históricas, representa o processo dialético de reassunção de uma identidade que, partindo de uma unidade imediata, cinde-se em movimentos reflexionantes de alteridade, diferenciação e separação para, finalmente, encontrar a sua realidade efetiva com a qual se reconcilia numa unidade superior a identidade da identidade e da diferença. Essa identidade reconciliada constitui a expressão lógica do processo, mediante o qual a realidade torna-se efetiva. A questão que se coloca para Hegel é como é possível compreender a racionalidade ética e social dessa realidade, particularmente aquela que se refere ao espírito objetivo o qual se realiza na história na esfera do direito e da política? E mais, como expressá-la pelo pensamento recorrendo ao seu fundamento ideal (das Ideal), portanto, à sua própria realidade sem saltar para uma explicação idealizada (das Ideal), a qual jamais se reconcilia com aquilo que a coisa é na sua realidade efetiva? O problema da reconciliação implica, portanto, a questão do realismo da Idéia em oposição ao idealismo subjetivo ou abstrato da idealidade do ideal, de tal modo que a sua racionalidade deve estar presente e operar de forma imanente à própria efetividade do real.

O Prefácio à Filosofia do Direito propõe esse realismo da Idéia ${ }^{15}$ e a sua forma temporal de apresentação no tempo presente como tarefa da filosofia: "Precisamente desta posição da filosofia diante da realidade (Wirklichkeit) é que surgem equívocos, e com isso volto ao que já dissera anteriormente: que a filosofia, por

questão de como "posso ser reconciliado com o mundo social" é uma questão filosófica importante, mesmo que não se aceite a resposta dada por Hegel.

15 Na Ciência da Lógica, o termo Idéia significa a unidade do conceito com o seu ser-aí. Ela compreende o aspecto ideal do conceito e a sua realidade empírica, o seu ser-aí (Dasein). Na Enciclopédia, Hegel insiste sobre os dois momentos da Idéia e da solidariedade dialética que eles representam. "A Idéia é o verdadeiro em si e para si, a unidade absoluta do conceito e da objetividade. Seu conteúdo ideal (ideeller Inhalt) não é outra coisa senão o conceito em suas determinações; seu conteúdo real é apenas sua [do conceito] exposição que ele se dá na forma de um ser-aí (Dasein) exterior, e esta figura (Gestalt) está incluída na sua idealidade, em seu poder, e, desse modo, o conceito se conserva nela" (Enzyklopädie der philosophischen Wissenschaften im Grundrisse. Werke 8, Frankfurt am Main; Suhrkamp, 1986, § 213). 
ser a investigação do racional (Vernünftigen), é, precisamente por isso, a compreensão do presente efetivo, e não a exposição de um além, sabe Deus onde deveria estar [...]" ${ }^{16}$ Pensar o tempo presente é papel da filosofia, e esse é o significado da reconciliação do pensamento com a realidade, tema que Hegel retoma de forma insistente contra as utopias construídas pelo formalismo voluntarista das filosofias da abstração do dever-ser. A força do realismo daquilo que é "o inteiramente presente"17 exprime-se, é bem verdade, pela idealidade, mas aquela que é derivada da categoria lógica da Idéia (die Idee), e não pelo vazio da idealidade do ideal (das Ideal). Por isso, a história deve ser o âmbito da realização reconciliadora entre aquilo que deve ser e aquilo que efetivamente é.

Se a esfera do verdadeiro for reduzida apenas àquilo que deve ser, então o presente torna-se uma má realidade, algo que deve ser desprezado, principalmente do ponto de vista moral e político, em nome da pureza do ideal. "O que torna os homens descontentes moralmente [...] é que em sua opinião o presente não corresponde aos fins que eles consideram como justos e bons [...] opõe-se às condições existentes aquilo que elas deveriam ser segundo a justiça. ${ }^{18}$ Essa interdição hegeliana de uma verdade que está além - a má infinitude - não elimina, contudo, o lado da idealidade do conceito. O presente comporta, sim, um além, mas ele está do lado de cá, na tensão dialética com o seu outro a boa infinitude. O além daquilo que é o seu conceito para ser realidade efetiva deve transpor a sua idealidade puramente conceitual, exprimindo-se em figurações concretas.

Esse lado ideal, derivado daquilo que está presente - a Idéia, exime a reconciliação hegeliana de duas possíveis deficiências: a pecha de conformismo (e mesmo de conservadorismo para com a vigência racional da realidade) e a acusação de relativismo historicista. No que diz respeito à primeira deficiência, é preciso compreender que a reconciliação não se traduz por uma acomodação à realidade do mundo e da história, a ela se resignando. Em seu movimento de apresentação, a Idéia se constitui também em crítica daquilo que está simplesmente aí. O famoso aforismo hegeliano "o que é racional é efetivo, e o que é efetivo é racional" poderia induzir a uma leitura legitimadora da realidade, na qual tudo o que existe, pelo simples fato de existir, deve ser considerado como algo racional, a ele se conformando. Se a verdade do mundo social (Sittlichkeit) não deve sofrer uma

${ }_{16}$ HEGEL, G. W. F. Grundlinien der Philosophie des Rechts oder Naturrecht und Staastswissenschaft im Grundrisse. Werke 7, Frankfurt am Main; Suhrkamp, 1986, Prefácio, p. 24

17 HEGEL, Enzyklopädie der philosophischen Wissenschaften im Grundrisse (1830). Ed. F. Nicolin e Pöggeler. Hamburg: Felix Meiner, 1969, § 213, Adendo, p. 369.

18 HEGEL, Die Vernunft in der Geschichte. Ed. J. Hoffmeister, Hamburg: Felix Meiner, 1996, p. 108. "O que Hegel está criticando é a noção de idealidade em Kant que erigiu a Idéia na dimensão do incondicionado: o conceito puro da razão, aquilo que não pode ser dado na experiência ou na realidade sensível. Hegel reprova nessa 'imagem originária à guisa de uma máxima', à qual estaríamos obrigados a nos aproximar, o seu caráter abstrato, indeterminado, que transforma a Idéia em idealidade no sentido de derivado do ideal (das Ideal). O ideal para Hegel não tem a conotação do ideal kantiano, pois, nesse caso, a Idéia permanece no além, como a infinitude para o entendimento. A realidade sem o seu conceito é mera sombra, algo que não é verdadeiro" (cf. RAMOS, C. A. Liberdade Subjetiva e Estado na Filosofia Política de Hegel. Curitiba: Editora da UFPR, 2000, p. 43). 
violência revolucionária, para ser o que ela deve ser, o filósofo defende uma aceitação realista da necessidade racional dos fatos históricos, inclusive alguns momentos revolucionários, como, por exemplo, a Revolução Francesa, que ele reputa como um movimento histórico positivo. O que Hegel quer dizer com esse aforismo é que a realidade, no seu processo de realização efetiva como Wirklichkeit, que não deve ser confundida com o mero existir (Dasein ou Existenz), o momento da sua racionalidade coincide com a sua efetivação, de tal modo que ela só alcança aquilo que ela é, quando realiza a sua racionalidade.

Quanto à segunda deficiência - a do relativismo historicista, é preciso compreender que o conceito de reconciliação, ao legitimar o presente, o faz por uma necessidade de ordem lógica. Não o necessitarismo da lógica do entendimento, que se vê enredada por um dualismo: ou bem a contingência e liberdade na negação unilateral da necessidade racional, ou bem esta necessidade na negação da liberdade. A racionalidade que Hegel postula não é algo que se põe como um além (dever-ser) dela mesma, porém deve estar reconciliada com ela na imanência lógica daquilo que é, mas que preserva o que ela também deve ser.

O cognitivismo hegeliano defende a tese aristotélica de que existe um núcleo de inteligibilidade do real que pode ser apreendido pela razão, e que essa apreensão exprime, justamente, a conciliação do pensamento com a realidade. Esse é o motivo pelo qual o filósofo idealista afirma sua profissão de fé realista, dizendo que "compreender o que é, esta é a tarefa da filosofia, pois o que é, é a razão. No que diz respeito ao indivíduo cada um é, de todos os modos, filho do seu tempo, da mesma maneira a filosofia também apreende seu tempo no pensamento. É tão insensato crer que uma filosofia qualquer ultrapassará o mundo presente, quanto acreditar que um indivíduo saltará por sobre seu tempo e transporá o Rhodes". ${ }^{19} \mathrm{O}$ mundo real deve ser objeto da filosofia, porque ele é racional, ou seja, ele permite apreender a lógica imanente da sua razão de ser. O que não significa conformismo, conservadorismo ou pessimismo. Significa realismo, cuja conotação valorativa, do ponto de vista político, está aderente à radical historicidade do mundo social. ${ }^{20}$

19 HEGEL, G. W. F. Grundlinien der Philosophie des Rechts,.., Prefácio, p. 26. A leitura hegeliana do provérbio "Hic Rodus, hic saltus" (aqui está o Rhodes, aqui está o seu salto) é vertida para o alemão como "Hier ist die Rose, hier tanze" (aqui está a rosa, dance aqui), onde Rhodes (Rodos) significa tanto a ilha de Rhodes, como também a rosa, e saltus (pular) é tomado, no alemão, no imperativo (tanze) do verbo dançar. A rosa é o símbolo da alegria, e a tarefa do pensamento é encontrar a alegria na cruz do presente, nele descobrindo a sua racionalidade.

${ }^{20}$ Hardimon no seu estudo demonstra que o termo alemão Versöhnung usado por Hegel não tem o sentido sugerido pela idéia corrente de reconciliação de submissão, resignação, aquiescência ou rendição. Antes denota afirmação, não no sentido de pura aceitação de coisas ou fatos que são assimilados sem julgamento ou avaliação, porém no sentido de que aquilo que é existe na positividade do ato de ser, mas, também, na sua negatividade e que o mundo real é um mundo contingente, imperfeito e repleto de deficiências e problemas. A relação dialética dessas duas dimensões só pode ser capturada pela categoria hegeliana da reconciliação. "Reconciliação é, então, compatível com uma relação mais ou menos ativista para com o mundo social. Embora não requeira um ativismo social, ela permite isso" (HARDIMON, Hegel's Social Philosophy. The Project of Reconciliation, p. 123. Cf., também, cap. 3 da mesma obra. "O conceito de reconciliação") 
No que diz respeito ao aspecto institucional, a tese hegeliana exposta no começo da Filosofia do Direito de que a "Idéia do direito é a liberdade: para apreendê-la verdadeiramente é preciso conhecê-la no seu conceito e no seu ser-aí (Dasein) que adota o conceito" ${ }^{21}$ adquire plausibilidade no contexto da especulação hegeliana, para a qual a filosofia deve compreender a realidade social, política e jurídica dos homens como o "ser-aí de todas as determinações da liberdade." Se a reconciliação está intrinsecamente vinculada com o sentido lógico da Idéia na qual a liberdade deve ser vista na articulação da idealidade (conceitual) com a sua realização que tem uma expressividade histórica, o desenvolvimento da Idéia revela-se em um determinado ser-aí do conceito autárquico de liberdade o seu aspecto histórico-institucional. A reconciliação significa que a Idéia (de liberdade) permanece consigo mesma, isto é, junto a si no seu outro.

Se a reconciliação apresenta esse lado auto-referente da liberdade que se põe como a expressão institucional da sua verdade com a qual devemos nos reconciliar, o lado intersubjetivo de relações de reconhecimento está, também, presente na reconciliação. A livre atividade do espírito humano na produção histórica das instituições sociais, culturais e políticas, que permite ao homem estar consigo mesmo na objetivação de suas ações, é constituída junto com os outros em relações de reconhecimento intersubjetivo. O direito, as instituições políticas e sociais são realizações comunitárias que trazem o sinal da sua própria razão de ser: a liberdade que não se reduz à sua dimensão meramente individual do subjetivismo moral auto-referente ou do juridicismo formal dos direitos. O caráter objetivo da liberdade traduz o aspecto da reconciliação dos indivíduos com essas instituições, nas quais eles se reconhecem reciprocamente como sujeitos livres com elas se reconciliando.

Tanto o aspecto lógico-histórico como o institucional da concepção hegeliana de reconciliação estão presentes no caráter explicativo que essa concepção possui no diálogo crítico com o pensamento filosófico produzido pela modernidade, a partir da tradição do direito natural moderno. ${ }^{22}$ A reconciliação revela-se com o poder lógico de promover uma verdadeira Aufhebung do conceito auto-referencial de liberdade tematizado pela filosofia moderna. Hegel pensa os novos tempos como a expressão de uma filosofia da história marcada pelo elemento da liberdade subjetiva, que deve ser reconciliada com o sentido substancial e comunitário dos antigos. O desacordo ou a cisão entre um e outro constitui o pathos da modernidade que perdeu o sentido da unidade da "bela eticidade" dos gregos, a qual não pode ser simplesmente restaurada. Com a aceitação do princípio da subjetividade

HEGEL, G. W. F. Grundlinien der Philosophie des Rechts, § 1, Adendo.

22 A Filosofia do Direito (1821) procura expor o princípio da modernidade, traduzido no "princípio da liberdade subjetiva" (Prinzip der subjektiven Freiheit), pelo qual se reconhece o valor formal (jurídico) da autonomia do sujeito e do seu valor como pessoa e como subjetividade. Os tempos modernos demonstraram a verdade histórica da liberdade subjetiva como o divisor espiritual da Europa moderna de outras épocas que carecem desse princípio. "O direito da particularidade do sujeito de encontrar sua satisfação ou, o que é o mesmo, o direito da liberdade subjetiva, constitui o ponto crítico e central na diferença entre o tempo moderno e a Antiguidade" (§ 124, Obs.). 
dos modernos, e com a valorização da autonomia do sujeito e do direito individual (Kant e Fichte), Hegel radicaliza a tendência do pensamento moderno, no sentido da construção de um sujeito auto-referente, mas que necessita reconciliar-se com a objetividade das instituições sociais e políticas, mediante ações de reconhecimento. Pretende, assim, que a sua própria filosofia seja a expressão máxima desse processo, na medida em que ela representa a consumação e, concomitantemente, a sua superação.

Para Hegel, o desafio da filosofia política consiste em reconciliar estas duas esferas dos tempos modernos, aparentemente irreconciliáveis: a liberdade individual auto-referente do individualismo burguês, que se exprime na dinâmica dos interesses da sociabilidade da esfera da Sittlichkeit da sociedade civil-burguesa, com a efetividade da liberdade na substancialidade ética da Sittlichkeit, da qual o Estado é a realização efetiva. ${ }^{23}$ Contudo, tal integração reconciliadora não pode realizar-se pela coerção violenta. A força do Estado consiste, precisamente, em fazer valer o seu idealismo político, pelo qual o poder do Estado é visto como uma "potência livre" que governa sem violência. Apenas a integração do indivíduo nessa substância permite, preserva a liberdade e, simultaneamente, desarma o inevitável conflito entre o privado (particular) e o público (universal), suprimindo a cisão sem coerção ou violência.

\section{Uma leitura de Rawls a partir do conceito hegeliano de reconciliação}

Rawls se ocupa do tema hegeliano da reconciliação na obra de Lectures on the History of Moral Philosophy no § 2 A Filosofia como Reconciliação do capítulo dedicado à Rechtsphilosophie de Hegel. Rawls interpreta esse tema de acordo com a tese hegeliana da racionalidade do mundo social e político que, exprimindo a liberdade, determina um vínculo entre a realidade e a forma de vida que é necessária para o homem e para as instituições sociais. Compreender isso é tarefa da filosofia (política) que não pode refugiar-se num dever-ser, mas reconciliar-se com a realidade como algo racional e necessário.

\footnotetext{
3 "Devido à complexidade do Estado moderno e das suas instituições, da amplitude do seu território e da dimensão da sua população, Hegel percebe que este Estado não pode retroceder ao ideal antigo. Os direitos da particularidade na modernidade, consignados na figura do homem burguês da sociedade civil-burguesa, exigem a diferenciação da unidade política da pólis. Isso significa, para Hegel, reconhecer a legitimidade da liberdade e os interesses privados dos indivíduos na modernidade. O desafio do Estado moderno está em evitar tanto a unilateralidade do substancialismo, presente na vida ética e política grega, como a unilateralidade do individualismo que se manifesta nas teorias políticas modernas. A filosofia política hegeliana inclina-se, então, para a conciliação da liberdade subjetiva com o sentido da totalidade comunitária, da vontade individual com os direitos da comunidade, enfim, do indivíduo com o Estado, da modernidade com a pólis" (cf. RAMOS, C. A. LiberdadeSubjetiva e Estado na Filosofia Política de Hegel, p. 17). Na observação de Ilting, "trata-se, então, segundo Hegel, de realizar sob as condições dos tempos modernos esta idéia da liberdade que reúne, não só o sentido de comunidade dos antigos, mas também a idéia moderna de indivíduo autônom." (ILTING, K. H. La Forme Logique et Systématique de la Philosophie du Droit, In: Hegel et la Philosophie du Droit. Paris: PUF, 1979, p. 58).
} 
Segundo Rawls, Hegel volta-se para o mundo social e racional (reasonable), pois, mediante as suas estruturas históricas, é que se pode garantir a liberdade. Isso induz Hegel a evitar a ética kantiana do Sollen, reivindicando a idéia da Sittlichkeit como uma totalidade de instituições políticas e sociais racionais que tornam a liberdade possível, e constitui a substância dos indivíduos. Kant não aprofundou o verdadeiro e último significado da autonomia que se realiza quando os homens, enraizados no mundo real da racionalidade, se compreendem pertencendo a este mundo e com ele estão reconciliados, e apenas nessa condição eles atuam livremente. Tão-somente uma ordem racional social ao coexistir com o aspecto da contingência, do acidente, da má sorte pode permitir a liberdade, tornando-a possível para que os indivíduos, por sua vez, realizem as suas liberdades pela mediação das instituições sociais e políticas. A Sittlichkeit hegeliana não prescreve aquilo que deve ser, mas propicia aos homens um mundo social e político efetivo com o qual eles devem se reconciliar. O que Hegel critica em Kant, observa Rawls, é o "desejo de pureza radical", de agir apenas "segundo a própria lei moral e nada mais". 24

Em que medida o viés interpretativo de Rawls ao conceito hegeliano da reconciliação permite estimar o valor desse conceito na sua obra? Evidentemente, o liberalismo político não faz um uso metafísico desse conceito, e nem de longe ele representa um elemento teórico para a compreensão da teoria rawlsiana. O que o filósofo norte-americano avalia como aspecto positivo na idéia hegeliana da reconciliação, e que pode ser reassumida sem as implicações políticas e metafísicas, é a intuição original de que a filosofia (política) deve ter a sensibilidade de compreender a diversidade de facetas que determinados conceitos básicos da cultura filosófica apresentam e possibilitam um consenso reconciliador dentro dos limites do conflito que o pluralismo razoável suscita.

Rawls sustenta que um dos vários papéis que a filosofia política possui, como parte da cultura, é o da reconciliação - o que foi devidamente enfatizado por Hegel. "Uma terceira função, destacada por Hegel em Filosofia do Direito (1821), é a da reconciliação: a filosofia política pode tentar acalmar nossa raiva e frustração contra a sociedade e sua história mostrando-nos como suas instituições, quando propriamente entendidas de um ponto de vista filosófico, são racionais, e se desenvolveram ao longo do tempo da maneira como o fizeram para atingir a sua forma racional atual [...] Ele nos propõe a reconciliação - Versöhnung, ou seja, devemos aceitar nosso mundo social positivamente, e não apenas nos resignar a ele". ${ }^{25}$ Ora, um dos aspectos dessa racionalidade presente nas sociedades modernas e que caracteriza o seu destino histórico é o "fato do pluralismo razoável". Diante desse fato, que não permite que uma sociedade democrática seja tomada como uma comunidade "um corpo de pessoas unidas por uma

RAWLS, J. Lectures on the History of Moral Philosophy, p. 335

RAWLS, J. Justiça como Eqüidade: Uma Reformulaçã, trad. Claudia Berliner. São Paulo: Martins Fontes, 2003, § 1, p. 4. 
mesma doutrina abrangente, ou parcialmente abrangente", ${ }^{26}$ não podemos demonstrar rejeição, mas com ele nos reconciliar.

Dois aspectos são importantes, segundo Rawls, para a filosofia, que pretende se reconciliar com a racionalidade dos tempos modernos. O primeiro diz respeito ao interesse de se buscar uma articulação dos princípios da igualdade com a liberdade; e o segundo refere-se à conexão entre a exigência normativa do ideal de uma justiça como eqüidade (justiça política) com os valores e as convicções históricas da realidade das sociedades democráticas modernas. Uma filosofia desse tipo é aquela que o filósofo norte-americano pretende constituir, e que ele julga ser um pensamento que não fere o "espírito" do conceito hegeliano de reconciliação.

Quanto ao primeiro ponto, Rawls entende ser preciso recuperar o papel reconciliador da filosofia política, possível se ela articular igualdade e liberdade. Para o filósofo, o "impasse da nossa cultura política pública" consiste no conflito entre duas tradições do pensamento democrático, uma associada a Locke, a outra a Rousseau. Enquanto a tradição derivada de Locke dá prioridade à chamada liberdade dos modernos, isto é, às liberdades civis, à liberdade de consciência e de pensamento, aos direitos básicos da pessoa, aos direitos de propriedade e de associação; a tradição oriunda de Rousseau atribui primazia ao princípio da igualdade de participação e à igual liberdade política para a defesa dos valores da vida pública, considerando as liberdades civis como subordinadas. O projeto de Rawls consiste em buscar uma teoria que possa reconciliar essas duas tradições com base num acordo suficiente para permitir a construção de uma teoria política da justiça que possa reconciliar os ideais da liberdade e da igualdade.

No que se refere ao segundo aspecto do sentido da reconciliação, ou seja, a conexão entre a exigência normativa do ideal de uma justiça como eqüidade com os valores e as com a realidade histórica do mundo moderno, o desafio e a originalidade de Ralws consiste na tentativa de encontrar uma concepção normativa dessa justiça (política) que esteja em consonância ou em harmonia com "as convicções e tradições mais enraizadas de um Estado moderno". ${ }^{27} \mathrm{Na}$ medida em que a sua teoria é

concebida como uma concepção política da justiça válida para uma democracia, ela deve tentar apoiar-se apenas nas idéias intuitivas que estão na base das instituições políticas de um regime democrático constitucional e nas tradições públicas que regem a sua interpretação. Trata-se de uma concepção política, em parte porque ela provém de uma certa tradição política. Esperamos que ela possa encontrar pelo menos o que podemos chamar de um consenso por justaposição, ou seja, um consenso que inclua todas as doutrinas filosóficas e religiosas contrapostas, que podem ser duradouras e encontrar adeptos numa sociedade democrática constitucional mais ou menos justa. ${ }^{28}$

\footnotetext{
Idem, ibid.

RAWLS, J. Justiça e Democracia, p. 156.

Idem, p. 204-205.
} 
Uma dessas convicções a que Rawls se refere é a evidência histórica do fato do pluralismo, fato esse que preocupa o filósofo após a publicação de Uma Teoria da Justiça, em torno do qual gira a questão básica do liberalismo, no final do século XX. O objetivo é adequar a sua teoria (de propor princípios normativos de uma justiça eqüitativa para regular uma sociedade justa, estável e cooperativa) ao fato do pluralismo razoável, procurando escoimar possíveis dúvidas e críticas que a sua análise suscitava, particularmente a noção de que o "tipo de liberalismo que ela representa é intrinsecamente deficiente porque se baseia numa concepção abstrata da pessoa e recorre a uma idéia individualista e não social da natureza humana". 29

Para poder encontrar uma concepção política da justiça que seja objeto de um "consenso por justaposição de doutrinas abrangentes razoáveis" e servir, assim, de base pública de justificação para a sociedade caracterizada pelo pluralismo razoável, o procedimento metodológico, para Rawls, se apresenta nas seguintes possibilidades: a) o uso do método do idealismo transcendental, recorrendo a princípios universais reguladores, ou a idéias puras da razão como padrões de representação definidores de como "deve ser" a realidade; ou b) o uso do método histórico dos princípios que são dados pela evidência social, antropológica ou psicológica obtida por meio da análise concreta de apresentação de idéias intuitivas que a realidade da sociedade oferece através dos tempos. De acordo com Rawls, ambas as possibilidades são insuficientes, se tomadas na parcialidade das suas posições: a primeira incorre no idealismo abstracionista formal, pois o que é justo deve ser derivado da natureza racional do homem segundo princípios que valem para todos; a segunda resvala para o relativismo histórico, uma vez que as regras morais são o reflexo sociocultural ou econômico de uma determinada configuração historicamente constituída.

Para resolver essas deficiências, a posição de Ralws não se inclina nem para a alternativa do universalismo das verdades éticas e jurídicas, e nem para o relativismo historicista. O filósofo adota a seguinte estratégia: utiliza o procedimento de apresentação de princípios presentes de forma implícita na cultura das sociedades democráticas; e, para evitar o relativismo, associa a esse procedimento uma forma de representação ideal, rejeitando, contudo, o seu formalismo idealista. Esse método pode ser chamado de abstracionismo concreto ou real, e que guarda uma certa semelhança com o recurso especulativo da noção de Idéia na análise hegeliana.

O elemento formal/normativo não decorre do apriorismo de ideais reguladores, mas de um procedimento ideal construtivo que opera a partir de certas idéias básicas presentes na realidade. A sua teoria da justiça "tenta estabelecer uma concepção idealizada de certas idéias intuitivas, fundamentais, como as da pessoa como ser livre e igual, de uma sociedade bem-ordenada e do papel público de uma concepção da justiça política, e que ela vincula essas idéias à idéia ainda

${ }^{29}$ RAWLS, J. Liberalismo Político. Trad. João S. Nunes. Lisboa: Editorial Presença, 1996, p. 25, 26. 
mais fundamental e geral da sociedade como sistema eqüitativo de cooperação, através do tempo, de uma geração à seguinte. Os direitos, os deveres e os fins são apenas elementos desse tipo de concepção idealizada. Assim, a teoria da justiça como eqüidade está de fato baseada em concepções ou, como Elisabeth Anderson me sugeriu, em ideais, já que essas idéias intuitivas fundamentais refletem ideais implícitos ou latentes na cultura pública de uma sociedade democrática" ${ }^{30} \mathrm{O}$ liberalismo político de Rawls articula, desse modo, o procedimento metodológico de apresentação de um "certo número de idéias básicas conhecidas, implícitas na cultura pública de uma sociedade democrática, ${ }^{, 31}$ com uma forma de construtivismo que as representa de modo normativo.

A validade de uma concepção política da justiça que seja aceitável para todos aqueles que se concebem como pessoas livres e iguais, que agem de modo racional e razoável e participam da cooperação social, não pode ser deduzida a partir de uma exigência em si mesma "transcendental". Assim, a formulação de uma concepção pertinente de liberdade e de igualdade deve estar

enraizada nas noções mais fundamentais de nossa vida política e que esteja de acordo com a nossa concepção de pessoa. Mas como chegar a esse objetivo? A teoria da justiça como eqüidade tenta descobrir as idéias fundamentais (latentes no bom senso) relativas à liberdade, à igualdade, à cooperação social e à pessoa formulando o que eu chamarei de concepções-modelos. ${ }^{32}$

O método abstracionista concreto ou real contido nas idéias "intuitivas fundamentais" ou nas "concepções-modelo" tem valor prático no sentido de dirimir o conflito, como também possui uma função heurística importante para se encontrar uma concepção política da justiça.

O trabalho de abstração não é gratuito: não se trata de abstrair por abstrair. Pelo contrário - diz o autor num longo comentário metodológico que vale a pena reproduzir, é uma forma de prosseguir a discussão pública, quando os entendimentos partilhados de menor generalidade soçobram. Devemos estar preparados para descobrir que, quanto mais profundo é o conflito, maior é o nível de abstração a que devemos ascender para obter uma perspectiva clara e descomprometida das suas raízes. Visto que os conflitos sobre a natureza da tolerância e sobre a base da cooperação para assegurar a igualdade têm persistido na tradição democrática, podemos supor que são profundos. Assim, para ligar esses conflitos com as coisas conhecidas e básicas, olhamos para as idéias fundamentais implícitas na cultura política pública [grifo nosso] e procuramos descobrir como é que os próprios cidadãos podem, após a reflexão devida, querer conceber a sua sociedade como um sistema eqüitativo de cooperação ao longo do tempo. Nesse contexto, é essencial formular concepções idealizadas da sociedade e da pessoa, por-

RAWLS, J. Justiça e Democracia, p. 220-221, nota 18.
RAWLS, J. Liberalismo Politico, p. 67.

RAWLS, J. Justiça e Democracia, p. 52, 53. 
tanto, necessariamente abstratas, [grifo nosso] associadas àquelas idéias fundamentais, para encontrar uma concepção política razoável da justiça. ${ }^{33}$

As noções kantianas de normatividade (conteúdo formal), razão prática (legitimação), autonomia e dignidade da pessoa são ingredientes teóricos presentes na teoria procedimental de J. Rawls, nela adquirindo características próprias. A pretensa vacuidade formal de instâncias normativas que asseguram a priori a validade incondicional de alguns princípios, independentemente das circunstâncias históricas e dos fatores sociais, é preenchida pelo recurso a determinadas concepções implícitas na tradição cultural das sociedades liberais democráticas modernas. Os cidadãos dessas sociedades aceitam certos procedimentos de acordo com as convicções mais profundas que refletem os legítimos anseios da sociedade. O formalismo apóia-se sobre uma base material e histórica da moralidade e da política das sociedades liberais modernas, e que inclui a concepção de pessoas livres, iguais e cooperativas no empreendimento social.

O problema da justiça desloca-se da sua fundamentação auto-referente (como é o caso das teorias morais perfeccionistas que propõem uma ordem moral independente, boa em si mesma) para a questão da sua justificação, através de um consenso das diversas e inevitáveis crenças individuais divergentes. Uma teoria da justiça deve ser compreendida, "não como uma concepção verdadeira, mas como base para o acordo político." Tal desiderato requer que se aplique o "princípio da tolerância à própria filosofia". Daí o interesse em "amenizar" o normativismo abstrato da teoria com a "racionalidade" dos tempos atuais, "reconciliando-se" com a realidade pluralista da sociedade liberal moderna.

O procedimentalismo de Rawls, enquanto resultado de um "equilíbrio reflexivo", é a expressão do espelhamento normativo da sociedade liberal moderna, no sentido de construir e sistematizar as convicções básicas dessa sociedade, mediante um procedimento de abstração. Esse procedimento revela-se no método das "concepções-modelo" (sociedade bem-ordenada, pessoa moral e posição original), cuja função normativa consiste na construção ideal de determinados princípios, evidenciados na realidade social das sociedades liberais modernas. Assim,

33 RAWLS, J. Liberalismo Político, p. 69. Ralws esclarece que o seu abstracionismo não é metafisicamente universalista como alguns críticos querem sugerir, por ex., M. Walzer. Segundo esse autor, o erro do universalismo consiste em transcender a particularidade cultural, as convencões, as tradições, as práticas de uma comunidade particular. Contra esse universalismo abstrato Walzer propõe um universalismo que ele chama de "reiterativo", o qual afirma que a criação de bens e de identidades com pretensão universal ocorre constante e reiteradamente e jamais da mesma maneira. As coisas humanas são, então, "parciais e incompletas" e uma teoria da justiça deve considerar essas particularidades e esse relativismo histórico. Rawls adverte contra o particularismo dessa posição, e que a sua filosofia política "não se 'ausenta', como muitos pensaram, da sociedade e do mundo. Nem pretende descobrir a verdade pelos seus métodos singulares de raciocínio, distintos de qualquer prática e pensamento políticos tradicionais" (Liberalismo Político, p. 68). Observa, ainda, que o seu abstracionismo não é uma fuga da realidade particular, e que "é um erro pensar que as concepções abstratas e os princípios gerais prevalecem sempre sobre os nossos juízos particulares" (idem, p. 69). Esclarece, por fim, que "estas duas faces do nosso pensamento prático [...] são complementares e devem ser ajustadas uma à outra para se constituírem numa perspectiva coerente" (idem, ibidem). 
para evitar uma interpretação ideal-formal que o kantismo sugere, Rawls recorre a diversas estratégias de "concretização" dessas concepções, e o faz recorrendo ao apelo da reconciliação com a realidade que o realismo da Idéia hegeliana já tinha aventado.

A idéia de reconciliação, sugerida por Hegel, significa o reconhecimento de que a chave para entender uma sociedade em um determinado tempo consiste em aceitar as instituições sociais e políticas dessa sociedade como a expressão de uma forma de sociabilidade que corporifica o "espírito" presente em uma época. Mutatis mutandis, Rawls vai ao encontro dessa idéia, ao dizer que cabe ao pensamento a tarefa de formular conceitualmente as práticas sociais em princípios razoáveis (porque são aqueles que pessoas racionais adotariam numa situação ideal) latentes ou implícitos na cultura pública das sociedades liberais modernas, permitindo a conciliação da teoria (da justiça) com a realidade.

A perspectiva de Rawls no Liberalismo Político, ao orientar-se pela aceitação de valores culturais, sociais e políticos das modernas sociedades liberais democráticas, que podem ser reguladas por uma concepção pública de justiça, remete ao elemento hegeliano de "reconciliação" do pensamento com a racionalidade do mundo em que vive a comunidade real dos homens em um dado momento histórico. Na sua preocupação em elaborar uma teoria afinada e em harmonia com a tradição histórica dos princípios da sociedade liberal democrática moderna e este é o escopo dos esclarecimentos posteriores presentes no Liberalismo Político pode-se dizer que as correções posteriores à Uma Teoria da Justiça, no sentido de propor uma interpretação política (não-metafísica) da sua teoria, não destoam da tese hegeliana de que a filosofia deve se voltar à realidade compreendendo-a segundo a exigência da sua racionalidade imanente.

Se os princípios da justiça como eqüidade não deixam de ter o caráter regulador de uma sociedade "bem-ordenada", eles não devem ser deduzidos por uma razão prática segundo os cânones de uma racionalidade que se realiza por exigência da sua intrínseca idealidade. Junto com o seu lado normativo, eles devem, também, ser a expressão de convicções que os indivíduos manifestam como membros da realidade de uma sociedade liberal moderna, na qual o reconhecimento público é produzido pela aceitação desses princípios como sendo eles mesmos justos segundo uma exigência racional publicamente partilhada.

Estimulado pela interpretação liberal de Hegel, Rawls compreende o desafio hegeliano de pensar a realidade no seu processo histórico de constituição segundo a medida conceitual nela imanente. Se esse pensamento não é assumido na sua inteireza e alcance filosóficos por Rawls, ele representa, pelo menos, um estímulo para quebrar as arestas da tendência do seu idealismo formal e abstrato de inspiração kantiana. A idealidade (concepção-modelo) de uma sociedade bemordenada deve ser justificada, não por si mesma, mas como um recurso que compreende a realidade presente de forma normativa. A propósito dos princípios normativos, ele escreve que 
não há necessidade de invocar doutrinas teológicas ou metafísicas para sustentar os seus princípios [de uma sociedade bem-ordenada], nem de imaginar um outro mundo que compensaria e corrigiria as desigualdades permitidas pelos dois princípios neste mundo. As concepções da justiça devem ser justificadas [grifo nosso] pelas condições de nossa vida como as conhecemos; caso contrário, não podem ser justificadas de forma alguma. ${ }^{34}$

Se o método rawlsiano não pode ser equiparado com o procedimento hegeliano do idealismo da Idéia, também é visível que o autor de Uma Teoria da Justiça procura evitar concepções forjadas pelo puro abstracionismo formal das concepções-modelo de pessoa, de sociedade bem ordenada e até mesmo da concepção original. Contudo, a tese rawlsiana de que os princípios de justiça são justificados por concepções-modelos implícitas ou latentes na cultura pública das sociedades democráticas não significa o abandono do formalismo. Significa apenas que é possível reconciliar o aspecto formal com o modo histórico da sua produção, de tal sorte que a exigência normativa e os ideais políticos possam representar uma perfeita adequação entre o formalismo das idéias e a sua vigência social institucionalizada.

A idéia de reconciliação é significativa, nessa perspectiva, porque os ideais que devem estar presentes no contexto institucional histórico de uma sociedade, mesmo que de forma implícita, são aqueles que os indivíduos aceitam, porque têm deles uma compreensão razoável e adequada ao seu tempo. Manifesta-se, assim, uma identidade entre os ideais de uma determinada configuração histórica e os valores morais normativos da pessoa e de uma sociedade bem-ordenada. Essa reconciliação se traduz nos valores que uma teoria política plenamente democrática supõe ser da sua cultura política.

A preocupação de Rawls revelou-se mais aguda naqueles pontos em que possíveis críticas de inspiração hegeliana poderiam revelar a necessidade de um melhor esclarecimento da sua teoria nos aspectos em que ela necessitaria de uma "correção" face aos seus "excessos" normativos. Essa tendência pode ser constatada nas revisitações a que o filósofo procede na sua teoria, e pode ser avaliada sob o estímulo da tese hegeliana da reconciliação do pensamento com a realidade, na tentativa de superar o normativismo abstrato destituído do necessário vínculo histórico, como apontam os críticos comunitaristas. ${ }^{35}$ Com efeito, se a "correção"

4 RAWLS, J. Uma Teoria da Justiça. Trad. Almino Piseto e Lenita M. R. Esteves. São Paulo: Martins Fontes, 1997, p. 504.

${ }^{35}$ As críticas de Taylor, notadamente aquelas que são endereçadas a J. Rawls, denunciam alguns aspectos do liberalismo político que, ao construir a sua teoria segundo um rigor procedimental, ignora determinados pressupostos, como, por exemplo: i) a prevalência de uma perspectiva individualista. O atomismo contemporâneo, sem fazer uso desse termo, herda a idéia de que a sociedade é constituída pelos indivíduos com vistas a realizar seus fins que são primeiramente individuais, e opera com esse pressuposto de forma acrítica, omitindo a condição radical do homem como ser social que depende da sociedade para a satisfação das suas necessidades afetivas, culturais, econômicas e políticas, bem como para a realização das suas capacidades humanas, como a razão, a sociabilidade e a linguagem, e cuja normatividade é dada pela construção social de um bem comunitário de pertencimento que tem prioridade sobre o justo; ii) a presença subjacente de valores co- 
hegeliana do formalismo abstracionista rawlsiano procede, então algumas teses do liberalismo político deixam de ser o antípoda absoluto das teses comunitaristas, particularmente aquelas de inspiração hegeliana, prevalecendo o princípio de "reconciliação" dessas duas teses.

As diferenças entre o liberalismo político de Rawls e o idealismo político de Hegel são imensas, mas, mesmo assim, o diagnóstico que eles efetuam diante da realidade social estimula a comparações de procedimentos que são relativamente similares. Tanto um como outro concordam com a tese de que a realidade social e histórica pode ser reconciliada com a medida da sua racionalidade, seja pela idealidade do conceito para Hegel, seja pela idealidade das concepções-modelos para Rawls. Para ambos, a estratégia da reconciliação significa tornar compatível a racionalidade dos ideais com a efetiva razoabilidade das ações humanas, e que a dimensão normativa que a racionalidade dos ideais representa na vida social não é estranha ao mundo real dessas ações.

\section{Referências}

HARDIMON, M. Hegel's Social Philosophy. Cambridge: Cambridge University Press, 1994.

HEGEL, G. W. F. Werk in zwanzig Bänden.Eds. E. Moldenhauer e K. M. Michel. Frankfurt am Main: Suhrkamp. 1986.

. Grundlinien der Philosophie des Rechts oder Naturrecht und Staatswissenschaft im Grundrisse,

Werk 7. Frankfurt am Main: Suhrkamp Verlag, 1970.

Linhas Fundamentais da Filosofia do Direito ou Direito Natural e Ciência do Estado em

Compêndio. Trad. Marcos Lutz Müller (Textos Didáticos), Campinas: Unicamp, 1996/8.

Enzyklopädie der Philosophischen Wissenschaften im Grundrisse. Herausgegeben von F. Nicolin e O. Pöggeler. Hamburg: Felix Meiner, 1969.

. Die Vernunft in der Geschichte. Ed. J. Hoffmeister Hamburg: Felix Meiner, 1996.

. Vorlesungen über die Philosophie der Geschichte, Werke 12. Werke in 20 Bänden. Frankfurt am Main: Suhrkamp, 1970.

ILTING, K. H. La Forme Logique et Systématique de la Philosophie du Droit, In: Hegel et la Philosophie du Droit. Paris: PUF, 1979.

LARMORE. C. The Morals of Modernity, Cambridge: Cambridge University Press, 1996.

MULHALL, J.; SWIFT, A. Liberals and Communitarians. Oxford : Blackwell,1992.

RAMOS, C. A. Liberdade Subjetiva e Estado na Filosofia Política de Hegel. Curitiba: Ed. UFPR, 2000.

"Hegel e o processo de auto-referencialidade da liberdade no direito natural moderno". In: Cadernos de História e Filosofia da Ciência. Campinas, Série 3, v. 12, n. 1-2, jan.-dez. 2002.

RAWLS, J. Uma teoria da justiça. Trad. Almiro Pisetta e Lenita M.R. Esteves. São Paulo: Martins Fontes, 1997.

munitários historicamente construídos e o abandono de necessários pressupostos culturais. A proposta rawlsiana, fortemente marcada por um procedimento abstrato, incorre na sedução de julgar a comunidade e a justiça segundo o olhar divino e regulador de uma razão que, engendrada pelas comunidades reais e concretas da história, delas se separa construindo um ideal político liberal que tem por pressuposto a pretensão da universalidade; iii) a idealização de valores morais da tradição liberal. A produção histórica de uma "razão desengajada" responsável pela criação, também histórica, de uma ética e de uma justiça procedimental é, ela, também, o resultado histórico de um racionalismo moderno, o qual está motivado na origem por uma visão do bem. 
Justiça e Democracia. Trad. Irene Paternot. São Paulo: Martins Fontes, 2000

. Lectures on the History of Moral Philosophy. Cambridge: Harvard University Press, 2000.

Liberalismo Político. Trad. João S. Nunes. Lisboa: Editorial Presença, 1996.

2003

. Justiça como Eqüidade. Uma Reformulação. Trad. Claudia Berliner. São Paulo: Martins Fontes,

. Kantian constructivism in moral theory. (The Dewey Lectures). In: The Journal of Philosophy, v. 77, p. 515-572, 1980.

SANDEL, M. Liberalism and the Limits of Justice. Cambridge: Cambridge University Press, 1982.

SCHWARZENBACH, S. Rawls, Hegel, and Communitarianism. In: Political Theory, vol. 19, n. 4, nov., 1991.

TAYLOR, C. Multiculturalism. Princeton : Princeton University Press, 1994.

. Hegel and Modern Society. Cambridge: Cambridge Univ. Press, 1978.

. As fontes do Self. A construção da Identidade Moderna. Trad. Adail U. Sobral e Dinah de Abreu Azevedo. São Paulo: Loyola, 1997.

. Le juste et le bien. In: Revue de Métaphysique et de Morale. 83, 1988

La Liberté des Modernes. Paris: PUF, 1997.

VITA, A. A justiça Igualitária e seus Críticos. São Paulo: Unesp, 2000.

WALZER, M. Las Esferas de la Justicia: una defesa del pluralismo y la igualdad. México: Fondo de Cultura Económica, 1983.

WILLIAMS, R. (ed.) Studies in Hegel's Philosophy of Right. New York: State University of New York, 2001.

WOOD, A. Hegel's Ethical Thought. Cambridge: Cambridge University Press, 1990. 